Acta Cryst. (1980). B36, 3212

\section{Molecular Structures and Dimensions}

The International Union of Crystallography and the Cambridge Crystallographic Data Centre announce the publication of the latest volume in this series: Volume 11, entitled Bibliography 1978-79, Organic and Organometallic Crystal Structures. It contains bibliographic information on 3023 structures published during 1978-1979. As in previous volumes the entries are arranged in 86 chemical classes and cover organic compounds, complexes and organometallic compounds. There are extensive indexes for authors, compound names and formulae.

The price of the new volume is 100 Netherlands guilders (about US \$53 at current rates of exchange). Personal copies may be purchased at a reduced price of 75 Netherlands guilders. Copies are available directly from D. Reidel Publishing Company, PO Box 17,3300 AA Dordrecht. The Netherlands. Alternatively, orders may be placed with Polycrystal Book Service, PO Box 11567, Pittsburgh, PA 15238, USA, or with any bookseller. Trade orders should be sent to Reidel.
Acta Cryst. (1980). B36, 3212

\section{Co-Editors of Acta Crystallographica}

Dr P. J. Wheatley, Department of Physical Chemistry, University of Cambridge. England, has resigned as a Co-Editor of Acta Crystallographica with effect from the end of 1980 and Dr T. J. Hamor. Department of Chemistry, University of Birmingham. England. has been appointed to succeed him, along with $\operatorname{Dr} \mathrm{S}$. Jagner and $\operatorname{Dr} \mathrm{B}$. T. M. Willis, whose appointments have been announced previously.

Acta Cryst. (1980). B36, 3212

\section{Report of the Executive Committee for 1979}

The Report of the Executive Committee for 1979 has been published in Acta Crystallographica. Section A [Acta Cryst. (1980). A36, 1072-1088]. It reports on the meetings and publications of the Union, the work of its Commissions, and the work of bodies not belonging to the Union on which the Union is represented. 